\title{
Global changes in oceanic mesoscale currents over the satellite altimetry record
}

Josue Martinez-Moreno ( $\nabla$ josue.martinezmoreno@anu.edu.au )

The Australian National University https://orcid.org/0000-0002-8348-1588

Andrew Hogg

Australian National University https://orcid.org/0000-0001-5898-7635

Matthew England

UNSW Sydney https://orcid.org/0000-0001-9696-2930

Navid C. Constantinou

The Australian National University

Andrew E. Kiss

The Australian National University

Adele Morrison

Australian National University https://orcid.org/0000-0002-9904-4980

\section{Article}

Keywords: Oceanic eddies, oceanic mesoscale dynamics, climate change, mesoscale variability, satellite altimetry record

Posted Date: October 20th, 2020

DOI: https://doi.org/10.21203/rs.3.rs-88932/v1

License: (c) (1) This work is licensed under a Creative Commons Attribution 4.0 International License.

Read Full License

Version of Record: A version of this preprint was published at Nature Climate Change on April 22nd, 2021. See the published version at https://doi.org/10.1038/s41558-021-01006-9. 


\section{Global changes in oceanic mesoscale currents over the satellite altimetry record}

Josué Martínez-Moreno ${ }^{1}$, Andrew McC. Hogg ${ }^{1}$, Matthew H. England ${ }^{2}$, Navid C. Constantinou ${ }^{1}$,

4 Andrew E. Kiss ${ }^{1}$ \& Adele K. Morrison ${ }^{1}$

${ }_{5}{ }^{1}$ Research School of Earth Science and ARC Centre of Excellence for Climate Extremes, Aus-

6 tralian National University, Canberra, ACT, Australia

$7 \quad{ }^{2}$ Climate Change Research Centre and ARC Centre of Excellence for Climate Extremes, Univer-

8 sity of New South Wales, Sydney, NSW, Australia

Oceanic eddies play a profound role in mixing tracers such as heat, carbon, and nutrients, thereby regulating regional and global climate. Yet, it remains unclear how global oceanic eddy kinetic energy has evolved over the past few decades. Furthermore, coupled climate model predictions generally fail to resolve oceanic mesoscale dynamics, which could limit their accuracy in simulating future climate change. Here we show a global statistically significant increase of the eddy activity using two independent observational datasets of mesoscale variability, one directly measuring currents and the other from sea surface temperature. Regions characterized by different dynamical processes show distinct evolution in the eddy field. For example, eddy-rich regions such as boundary current extensions and the Antarctic Circumpolar Current show a significant increase of $2 \%$ and $5 \%$ per decade in eddy activity, respectively. In contrast, most of the regions of observed decrease are found in the tropical oceans. Because eddies play a fundamental role in the ocean transport of heat, momentum, 
and carbon, our results have far-reaching implications for ocean circulation and climate, and the modelling platforms we use to study future climate change.

Changes in the climate system over recent decades have warmed the upper ocean and modified the wind stress, heat and freshwater fluxes that drive ocean circulation $\frac{112}{2}$. These changes have the capacity to modify the ocean circulation at all scales, including the overturning circulation ${ }^{34}$, basin-scale gyres $\sqrt{5}$, boundary currents ${ }^{718}$, and the mesoscale ${ }^{9}$. The ocean's mesoscale incorporates motions that occur at spatial scales from $\sim 10$ to $\sim 100 \mathrm{~km}$. These motions include both steady flows, such as jets and re-circulations, and time-varying flows, generally referred to as eddies. Mesoscale eddies are ubiquitous in the global ocean and feed back onto all scales, from regional processes ${ }^{10}$ up to the meridional overturning circulation ${ }^{3}$. Moreover, these eddies act to transport and mix tracers such as heat, salt, and nutrients ${ }^{11,12}$. Thus, understanding the evolution of the mesoscale circulation is crucial to better predict our changing oceans.

Kinetic energy (KE) quantifies the magnitude of ocean currents $9913-15$. Kinetic energy is proportional to the square of the velocity, and is commonly separated into the mean KE (MKE; computed from the time-mean velocity field) and the KE of the time-varying velocity (known as the Eddy Kinetic Energy; EKE). The EKE is dominated by mesoscale variability and is a significant fraction of the total $\mathrm{KE}^{16,17}$. A recent study has inferred a global increase of KE anomaly from ocean reanalyses and ARGO floats ${ }^{15}$. However, these reanalyses and observations do not have the spatial resolution required to resolve the mesoscale field. Satellite observations, which can resolve the mesoscale, suggest that EKE in the Southern Ocean has a robust increasing trend $\sqrt{9}[18 \sqrt[19]{\text {. How- }}$ 
ever, there have been no studies that have quantified the global evolution of mesoscale variability from satellite observations. This is the goal of the present study.

Mesoscale ocean flow has a footprint in both sea surface height (SSH) and sea surface temperature (SST). EKE can be directly inferred from SSH via geostrophy, and mesoscale turbulence also acts to strain and shear the temperature field, meaning that regions of high EKE are associated with strong SST gradients. Therefore, observed gradients in SST can be considered a proxy for mesoscale variability $20-22$.

In this study, we examine the mesoscale evolution of the ocean from satellite observations of sea surface height (SSH) and sea surface temperature (SST) over the available satellite altimetry record (1993 - 2019). We use two independent datasets, namely AVISO+ SSH and NOAA optimal interpolated sea surface temperature (OISST) ${ }^{23}$, to estimate EKE and SST gradients respectively. These fields are then temporally smoothed using a running average of 12 months; the trends and the significance of each field are computed using a linear regression and a modified Mann-Kendall $\operatorname{tes}^{24}$ (see Methods for further details). We explore the mesoscale time-series for the global ocean, for individual ocean basins, and over regions characterized by their dynamical properties.

\section{Surface ocean acceleration}

Over recent decades, sea water thermal expansion and melting of land ice have led to an increase of $\mathrm{SSH}^{125}$ (Fig. 1a). This $\mathrm{SSH}$ increase can be observed in all ocean basins, but there is also regional variability (Fig. 1b). SSH gradients are proportional to the surface geostrophic flow, from which we can compute velocity anomalies and Eddy Kinetic Energy (see Methods). The time- 

${ }_{81} \pm 2.46 \times 10^{6}{ }^{\circ} \mathrm{C} m$ decade ${ }^{-1} ; 95 \%$ confidence level) relative to the time-mean globally integrated

mean EKE highlights mesoscale-rich regions including boundary currents and their extensions, the Antarctic Circumpolar Current (ACC), and the equatorial band (Fig. 11). More importantly, these oceanic mesoscale-dominated sectors show significant trends over the satellite altimetry record 1993-2019 (Fig. 1f; and contours in Fig. 11), which suggest a long-term adjustment of the global ocean mesoscale field. In particular, the surface globally-integrated EKE trend is positive $\sim 0.56 \%$ per decade (95\% confidence level). The spatial structure of EKE trends is highly heterogeneous, although its zonal average shows some significant net tendencies, with increasing trends polewards of $25^{\circ} \mathrm{S}$ and $40^{\circ} \mathrm{N}$ (Fig. 17,f). A strengthening of the EKE field is a direct indication of an increase in mesoscale activity.

Sea Surface Temperature (SST) is an independent dataset relative to SSH, but is also influenced by mesoscale activity and has better temporal and spatial resolution than SSH. SST has increased on multi-decadal timescales due to climate change ${ }^{26 / 27}$ (Fig. 22 $)$, with the global spatial pattern also modulated by interdecadal climate variability. This increase is spatially heterogeneous, with positive trends found in western boundary current regions $\mathrm{s}^{7}$ and over much of the subtropical gyres, and decreasing trends in the southeast Pacific, the far north Atlantic, and parts of the Southern Ocean (Fig. 2b). In contrast, the largest time-mean SST gradients are located in dynamic mesoscale regions, such as boundary currents, their extensions, and the ACC (Fig. 22d). Regions with large SST gradients also exhibit the largest positive SST gradient trends, while the subtropical gyres and the tropics mostly exhibit a decreasing trend (Fig. 2e-f; contours in $2 \mathrm{~d}$ ). The globally integrated SST gradient magnitude shows a significant increasing trend of $0.42 \%$ per decade (5.76 
SST gradient magnitude $\left(1.36 \times 10^{9}{ }^{\circ} \mathrm{C} m\right)$. Moreover, mesoscale eddies enhance the strength of SST gradients on small length scales, and further analysis (Fig. S3) shows that mesoscale SST gradients, characterized by features with horizontal length scales smaller than $3^{\circ}$, dominate the observed trends. The globally integrated mesoscale SST gradient magnitude has increased at a rate of $6.13 \pm 2.40 \times 10^{6}{ }^{\circ} \mathrm{C} m$ decade $e^{-1}$; significant at the $95 \%$ confidence level. The observed SST gradient signal appears to be an intrinsic response to the mesoscale field, consistent with the observed patterns of trends of the mesoscale EKE variability.

Eddy kinetic energy and mesoscale SST gradients show analogous spatial and temporal responses in the boundary currents and their extensions, the ACC and the tropics. Note that eddy-rich regions such as the Kuroshio, the Agulhas, the Gulf Stream, and the ACC show large changes in mesoscale SST gradients co-located with some of the largest EKE increases (Fig. 3). Even though we do not expect the fields to match perfectly, the areas with same-sign trends match to a good extent (Fig. S4). The similarity between these two independent satellite products reaffirms the intrinsic response of the mesoscale processes to a changing and variable climate.

\section{Spatial patterns of ocean mesoscale trends}

Mesoscale EKE and SST gradient trends both indicate a net strengthening of the global mesoscale. However, both datasets reveal heterogeneous patterns of trends. To further understand the spatial variability, we first focus our analysis on individual area weighted regions: namely, the Southern Ocean (south of $35^{\circ} \mathrm{S}$ ), and the Pacific, Indian, and Atlantic Oceans north of $35^{\circ} \mathrm{S}$ (Fig. 4d). This analysis reveals that the Southern Ocean and the Pacific Ocean are, to a large 
extent, responsible for the globally integrated trends and variations of EKE and mesoscale SST gradients; the trends in the Indian and Atlantic Oceans are in contrast much smaller (Fig. 4a,b). The Southern Ocean shows a significant increase for both the EKE and SST gradient, however, the Pacific Ocean SST gradient decreases significantly, while the EKE signal also decreases (albeit below 95\% significance level; Fig. 44,e). The large uncertainty in the Pacific EKE trend (orange error bars in Fig. 4c) is a consequence of the pulses in the time series during 1997 and 2015, both being El Niño onset years. These large anomalous interannual signals dominate the uncertainty of the global EKE trend, so that the global trends reported here are only just statistically significant at the $95 \%$ confidence level.

Over the satellite altimetry record, the strongest El Niño events occurred during 1997-1998 and 2015-2016 $\sqrt{28 / 29}$ (gray bars in Fig. 44,b). These El Niño events correlate with large pulses in the Pacific EKE signal, resulting in large uncertainty in the calculated global trends (Fig. 4)). El Niño events are associated with a strengthening of the North Equatorial Countercurrent and the northern branch of the South Equatorial Current particularly during extreme eastern Pacific El Niños, such as occurred during 1997-1998 and 2015-2016 $6^{30}$. During such El Niño events, the equatorial currents generate significant transient circulation anomalies extending over the equatorial band $\left(9^{\circ} \mathrm{N}\right.$ $\left.-9^{\circ} \mathrm{S}\right)$. After a scale decomposition of the velocities, we observe that these EKE pulses correspond to features located within the equatorial band and have scales larger than the typical mesoscale eddy size (see Methods; Fig. S5a,c). Thus, we conclude that modulation of the equatorial currents during El Niño events are responsible for these distinct year-long EKE pulses. 
To further investigate the effect of El Niño events on the mesoscale, we remove the equatorial regions $\left(9^{\circ} \mathrm{S}-9^{\circ} \mathrm{N}\right)$ and repeat the global trend analysis for EKE and SST gradients. The globally integrated extratropical EKE and SST gradient trends increase, while the corresponding uncertainty decreases; namely, EKE trends are now $1.46 \% \pm 0.24 \%$ per decade and SST gradients trends are $1.24 \% \pm 0.17 \%$ per decade (see striped bars in Fig. 4 c,e); both significant at the 95\% confidence level. It is thus clear that mesoscale activity in the Pacific, and particularly in the equatorial region, is strongly influenced by interannual variability.

The observed changes in EKE and SST of whole ocean basins still integrate over large heterogeneous regions with opposing trends. For example, the Pacific Ocean aggregates the strengthening of the equatorial currents in the equatorial Pacific Ocean during El Niño events, boundary currents, and the broader-scale oceanic gyres. These dynamical regions are not unique to the Pacific Ocean; the Atlantic and Indian basins also span over diverse dynamical regions. Therefore, we further decompose the ocean into dynamical regions (Fig. 5 d): namely, the Antarctic Circumpolar Current (ACC), the boundary currents and their extensions, the equatorial regions, and the subtropical ocean gyres (see Methods for dynamical region definitions). The remaining regions are grouped together. We now investigate the variability and trends within each of these dynamical regions.

Globally, there is a significant increase of EKE and SST gradients, however, each dynamical region shows a different response (Fig. 5). For example, the ACC region shows a significant increase in both EKE and SST gradients, consistent with an increase in wind stress there, as demon- 
strated in previous studies 13,31 . Boundary currents and their extensions collectively show a similar net response, in which EKE and SST gradients both increase. Individually, SST gradients increase in all boundary currents, however EKE in the Agulhas retroflection, the East Australian Current, the Leeuwin Current and the Malvinas Current have significantly increased, but the Gulf Stream and the Kuroshio Current do not show a significant net strengthening ${ }^{32} 33$ (Fig. S6); instead, regions of increase and decrease tend to cancel each other out in an area-average, particularly for the Kuroshio Current (Fig. 1f). The response seen in the Gulf Stream and Kuroshio Currents is consistent with the idea that these currents have shifted polewards ${ }^{734}$ and readjusted to climate modes $^{35}$. Note that a poleward shift cannot be captured by our static climatological definition of the boundary currents (see Methods). Moreover, regions outside the dynamical regions exhibit a significant increase of EKE and SST gradients, comparable to those of the more energetic regions. Thus, the observed increase of these remaining regions could be a consequence of the poleward shift of the boundary currents, particularly in the Northern Hemisphere.

There are two dynamical regions that do not exhibit an increasing trend (Fig. 5). The equatorial region is, again, dominated by interannual variability, where the largest changes correspond to El Niño events in both the EKE and mesoscale SST gradient time series. The mesoscale SST gradients show a significant decrease, which suggests a reduction of the mesoscale variability. However, the equatorial EKE trends are insignificant, due to the dominance of interannual variability in the signal. Similarly, subtropical gyre mesoscale SST gradients have decreased significantly over the past few decades, while the EKE trend is negative, but not significant. This observed decrease of SST gradients across the tropics and subtropics (Fig. 2) could result from the displacement of 
the extratropical atmospheric circulation $\frac{36}{37}$ (Hadley cells) and expansion of the tropics ${ }^{38}$, which could explain the decreasing SST gradient trends in the tropics due to homogenization of the tropical surface SST gradients. Thus, the SST gradients induced by mesoscale stirring are expected to reduce as the surface ocean becomes more thermally homogeneous. However, a longer record is required to separate the mesoscale response from interannual-decadal climate variability.

We have analysed the available satellite altimetry record of SSH and SST to reveal a significant global intensification of the mesoscale field over the satellite record, where eddy-rich regions such as boundary current extensions and the Antarctic Circumpolar Current present a significant strengthening of $2 \%$ and $5 \%$ respectively. This increase is most apparent in regions where eddies are already strong, such as the Southern Ocean as well as boundary currents and their extensions. This mesoscale signature is observed in both eddy kinetic energy and mesoscale sea surface temperature gradients. Note that these observed trends only capture the ocean's surface. If we assume that the mesoscale flow extends vertically to around $500 \mathrm{~m}$ depth (a reasonable assumption given the vertical structure of the gravest mode $\mathrm{e}^{(39}$ ), then the EKE trends imply a significant change in the global mesoscale energy budget of $0.42 \%-0.93 \%\left(0.05-0.12 \times 10^{18}\right.$ Joules $)$ over the satellite altimetry record ${ }^{40}$. Given the importance of mesoscale eddies for the redistribution of carbon and heat by the oceans, in addition to their capacity to control climate on regional to global scales, understanding this signal is crucial for improving future predictions of our oceans under anthropogenic forcing. Furthermore, current generation climate models used for climate projections (CMIP6) do not generally resolve eddies ${ }^{41}$; thus, important climatic adjustments driven by eddy-forced changes are likely to be missing from these simulations. 
The mesoscale evolution described here cannot be captured by coarse-resolution reanalysis products and sparse ARGO float observations, as previously used in other studies ${ }^{15}$. Here we used eddy-permitting satellite observations to reveal an insignificant decrease in EKE over the tropics, while reanalysis products suggest the tropics is where KE has recently increased the most. To better understand this discrepancy, we revisited the analysis for the oceanic KE time-anomaly, as undertaken by $\mathrm{Hu}$ et al ${ }^{[15}$, using our eddy-permitting satellite-derived KE. The results obtained are almost identical to the trends we presented in the analysis above (Fig. S7), yet strikingly different from those obtained by Hu et al. using non-eddy-resolving data (cf. their Fig 2a). This suggests that the inability of reanalyses and the Argo dataset to resolve the mesoscale, due to coarse-resolution and sparse sampling, leads to different estimates for regional kinetic energy trends. In addition, as we have demonstrated, the tropics are strongly influenced by interannual variability (e.g. El Niño), and yet the KE time-series from coarse reanalysis data do not detect the two extreme El Niño events observed in the satellite record. Thus, data resolution is the likely cause of the discrepancy between our eddy-permitting analysis and the results from the prior work using coarse-resolution reanalysis products 15

We investigated several hypotheses in order to explain the observed trends including (1) changes in winds (wind curl, wind stress), (2) changes in stratification, and (3) changes in largescale temperature gradients. The drivers of the observed trends are likely to be a combination of (1) non-local increases of winds, (2) outcropping and tilting of isopycnals, and (3) strengthening of baroclinic instability. However, the changes of winds, isopycnals and baroclinic growth rate are small, highly variable and sparse. Thus, better observational records are required to understand 
the increase in EKE observed from satellites. Moreover, as discussed above, coarse-resolution reanalysis products differ significantly from the mesoscale evolution we could detect from observed satellite altimetry. Thus, an in-depth analysis of the mesoscale evolution should be explored in more detail using eddy-resolving global ocean models and/or reanalyses.

Our study has documented major global scale reorganisation of the ocean's mesoscale kinetic energy observed over the past three decades. These observed adjustments in the mesoscale field have the potential to affect ocean circulation at all scales, and to modify the transport and redistribution of tracers, such as heat, carbon, and nutrients. Our findings thus have major implications for ocean readjustment to a changing climate.

1. Pörtner, H. et al. IPCC, 2019: IPCC special report on the ocean and cryosphere in a changing climate. IPCC 201942 (2019).

2. Intergovernmental Panel on Climate Change. Working Group 1, S. et al. Climate Change 2007 - The Physical Science Basis: Working Group I Contribution to the Fourth Assessment Report of the IPCC. Assessment report (Intergovernmental Panel on Climate Change).: Working Group (Cambridge University Press, 2007).

3. Marshall, J., Scott, J. R., Romanou, A., Kelley, M. \& Leboissetier, A. The dependence of the ocean's MOC on mesoscale eddy diffusivities: A model study. Ocean Modelling 111, 1-8 (2017). 
4. Toggweiler, J. R. \& Russell, J. Ocean circulation in a warming climate. Nature 451, 286-8 (2008).

5. Yang, H. et al. Poleward Shift of the Major Ocean Gyres Detected in a Warming Climate. Geophysical Research Letters 47 (2020).

6. Sutton, R. T. \& Hodson, D. L. R. Climate Response to Basin-Scale Warming and Cooling of the North Atlantic Ocean. Journal of Climate 20, 891-907 (2007).

7. Wu, L. et al. Enhanced warming over the global subtropical western boundary currents. Nature Climate Change 2, 161-166 (2012).

8. Kwon, Y.-O. et al. Role of the Gulf Stream and Kuroshio-Oyashio Systems in Large-Scale Atmosphere-Ocean Interaction: A Review. Journal of Climate 23, 3249-3281 (2010).

9. Hogg, A. M. et al. Recent trends in the Southern Ocean eddy field. Journal of Geophysical Research: Oceans 120, 257-267 (2015).

10. Radko, T. \& Marshall, J. Eddy-Induced Diapycnal Fluxes and Their Role in the Maintenance of the Thermocline. Journal of Physical Oceanography 34, 372-383 (2004).

11. Chelton, D. B., Gaube, P., Schlax, M. G., Early, J. J. \& Samelson, R. M. The influence of nonlinear mesoscale eddies on near-surface oceanic chlorophyll. Science 334, 328-32 (2011).

12. Early, J. J., Samelson, R. M. \& Chelton, D. B. The Evolution and Propagation of Quasigeostrophic Ocean Eddies. Journal of Physical Oceanography 41, 1535-1555 (2011). 
13. Meredith, M. P., Garabato, A. C., Hogg, A. M. \& Farneti, R. Sensitivity of the Overturning Circulation in the Southern Ocean to Decadal Changes in Wind Forcing. Journal of Climate 25, 99-110 (2012).

14. Busecke, J. J. M. \& Abernathey, R. P. Ocean mesoscale mixing linked to climate variability. Science Advances 5, eaav5014 (2019).

15. Hu, S. et al. Deep-reaching acceleration of global mean ocean circulation over the past two decades. Science Advances 6, eaax7727 (2020).

16. Wyrtki, K., Magaard, L. \& Hager, J. Eddy energy in the oceans. Journal of Geophysical Research 81, 2641-2646 (1976).

17. Chelton, D. B., Schlax, M. G., Samelson, R. M. \& de Szoeke, R. A. Global observations of large oceanic eddies. Geophysical Research Letters 34, L15606 (2007).

18. Patara, L., Böning, C. W. \& Biastoch, A. Variability and trends in Southern Ocean eddy activity in $1 / 12^{\circ}$ ocean model simulations. Geophysical Research Letters 43, 4517-4523 (2016).

19. Martínez-Moreno, J., Hogg, A. M., Kiss, A. E., Constantinou, N. C. \& Morrison, A. K. Kinetic energy of eddy-like features from sea surface altimetry. Journal of Advances in Modeling Earth Systems 11, 3090-3105 (2019).

20. Yuan, Y. \& Castelao, R. M. Eddy-induced sea surface temperature gradients in Eastern Boundary Current Systems. Journal of Geophysical Research: Oceans 122, 4791-4801 (2017). 
21. Castellani, M. Identification of eddies from sea surface temperature maps with neural networks. International Journal of Remote Sensing 27, 1601-1618 (2006).

22. Holladay, C. G. \& O’Brien, J. J. Mesoscale Variability of Sea Surface Temperatures. Journal of Physical Oceanography 5, 761-772 (1975).

23. Banzon, V., Smith, T. M., Steele, M., Huang, B. \& Zhang, H.-M. Improved Estimation of Proxy Sea Surface Temperature in the Arctic. Journal of Atmospheric and Oceanic Technology 37, 341-349 (2020).

24. Yue, S. \& Wang, C. The Mann-Kendall Test Modified by Effective Sample Size to Detect Trend in Serially Correlated Hydrological Series. Water Resources Management 18, 201-218 (2004).

25. Polito, P. S. \& Sato, O. T. Global Interannual Trends and Amplitude Modulations of the Sea Surface Height Anomaly from the TOPEX/ Jason-1 Altimeters. Journal of Climate 21, 2824-2834 (2008).

26. Cane, M. A. et al. Twentieth-Century Sea Surface Temperature Trends. Science 275, 957-960 (1997).

27. Ruela, R., Sousa, M. C., deCastro, M. \& Dias, J. M. Global and regional evolution of sea surface temperature under climate change. Global and Planetary Change 190, 103190 (2020).

28. Johnson, G. C., McPhaden, M. J., Rowe, G. D. \& McTaggart, K. E. Upper equatorial Pacific Ocean current and salinity variability during the 1996-1998 El Niño-La Niña cycle. Journal of Geophysical Research: Oceans 105 (2000). 
29. McPhaden, M. J. The child prodigy of 1997-98. Nature 398, 559-561 (1999).

30. Wang, L.-C. \& Wu, C.-R. Contrasting the Flow Patterns in the Equatorial Pacific Between Two Types of El Niño. Atmosphere-Ocean 51, 60-74 (2013).

31. Hughes, C. W. \& Wilson, C. Wind work on the geostrophic ocean circulation: An observational study of the effect of small scales in the wind stress. Journal of Geophysical Research: Oceans (1978-2012) 113, C02016 (2008).

32. Ezer, T., Atkinson, L. P., Corlett, W. B. \& Blanco, J. L. Gulf Stream's induced sea level rise and variability along the U.S. mid-Atlantic coast: Gulf Stream induces coastal sea level rise. Journal of Geophysical Research: Oceans 118, 685-697 (2013).

33. Uchida, H. \& Imawaki, S. Estimation of the sea level trend south of Japan by combining satellite altimeter data with in situ hydrographic data. Journal of Geophysical Research $\mathbf{1 1 3}$ (2008).

34. Yang, H. et al. Intensification and poleward shift of subtropical western boundary currents in a warming climate. Journal of Geophysical Research: Oceans 121, 4928-4945 (2016).

35. Piecuch, C. G. Likely weakening of the Florida Current during the past century revealed by sea-level observations. Nature Communications 11, 3973 (2020).

36. Saenko, O. A., Fyfe, J. C. \& England, M. H. On the response of the oceanic wind-driven circulation to atmospheric CO2 increase. Climate Dynamics 25, 415-426 (2005). 
37. Gupta, A. S. et al. Projected Changes to the Southern Hemisphere Ocean and Sea Ice in the IPCC AR4 Climate Models. Journal of Climate 22, 3047-3078 (2009).

38. Seidel, D. J., Fu, Q., Randel, W. J. \& Reichler, T. J. Widening of the tropical belt in a changing climate. Nature Geoscience 1, 21-24 (2007).

39. Sanchez de La Lama, M., LaCasce, J. H. \& Fuhr, H. K. The vertical structure of ocean eddies. Dynamics and Statistics of the Climate System 1, dzw001 (2016).

40. Wunsch, C. \& Ferrari, R. Vertical mixing, energy and the general circulation of oceans. Annual Review of Fluid Mechanics 36, 281-314 (2004).

41. Haarsma, R. J. et al. High Resolution Model Intercomparison Project (HighResMIP v1.0) for CMIP6. Geoscientific Model Development 9, 4185-4208 (2016).

42. Wolter, K. \& Timlin, M. S. Measuring the strength of ENSO events: How does 1997/98 rank? Weather 53, 315-324 (1998).

43. Lagerloef, G. S. E., Mitchum, G. T., Lukas, R. B. \& Niiler, P. P. Tropical Pacific near-surface currents estimated from altimeter, wind, and drifter data. Journal of Geophysical Research: Oceans 104, 23313-23326 (1999).

\section{Acknowledgments}

We thank Ryan Holmes for clarifying the equatorial response of El Niño events during 1997-1998 and 2015-2016. The satellite altimetry products were produced by Ssalto/Duacs and distributed by AVISO+, with support from CNES (https://www.aviso.altimetry.fr/ 

en/data/products/sea-surface-height-products/global/gridded-sea-level-heigh

317 html). All datasets are available in netCDF format at https:// doi.org/10.5281/zenodd. 3993824. Additional information and notebooks that reproduce the figures can be found at https://github.com/josuemtzmo/EKE_SST_trends. J. M.-M. was supported by the Consejo Nacional de Ciencia y Tecnología (CONACYT), Mexico funding. A. K. M. was sup-

ported by the Australian Research Council DECRA Fellowship DE170100184. Analyses were undertaken on the National Computational Infrastructure in Canberra, Australia, which is supported by the Australian Commonwealth Government. 

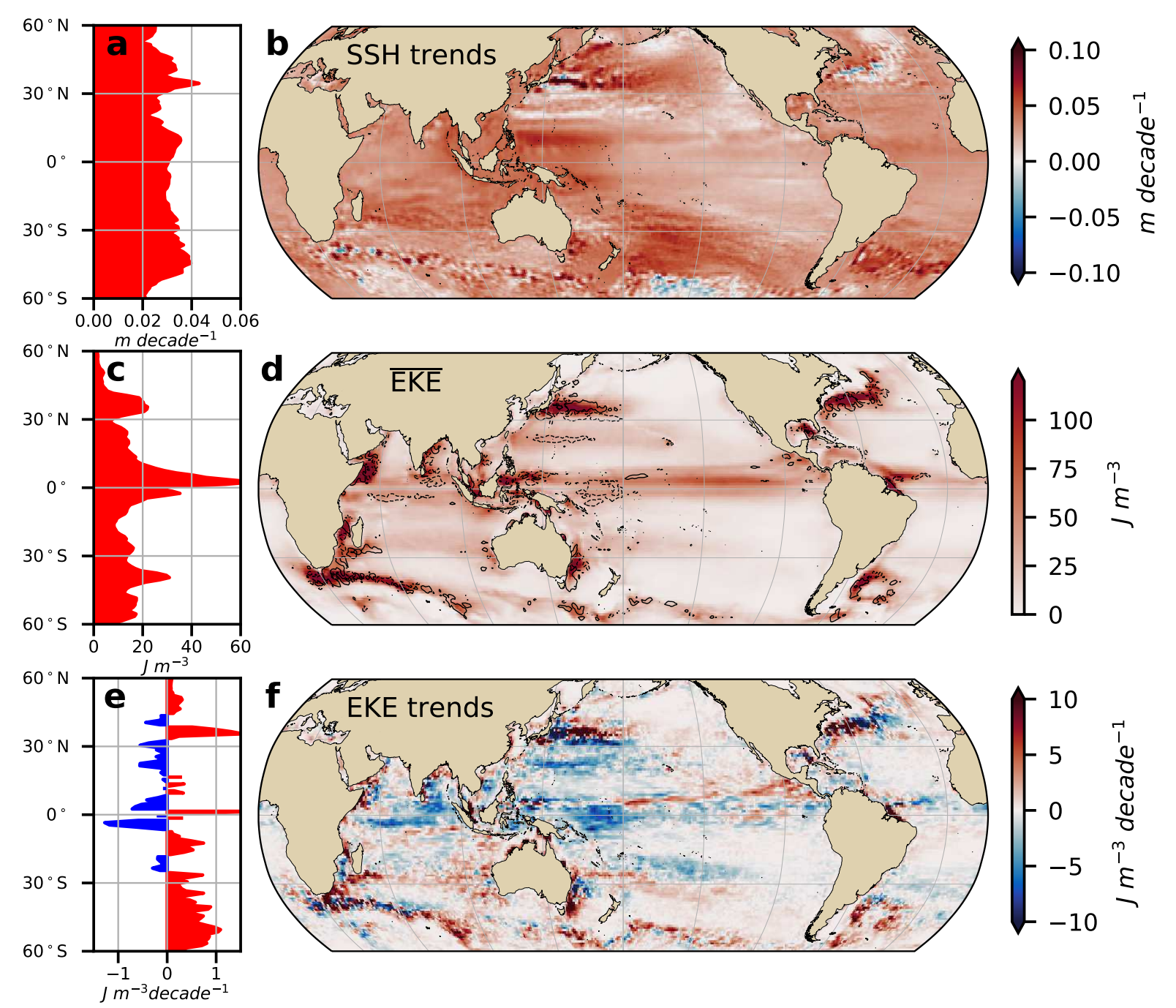

Figure 1 Sea Surface Height trend, mean surface Eddy Kinetic Energy and surface Eddy Kinetic Energy trend between 1993-2019 (a) Zonally averaged SSH trend; (b) map of SSH trend $(92.1 \%$ of global area is significant above $95 \%$ confidence level; for spatial distribution refer to Fig. S1); (c) zonally averaged mean EKE; (d) map of mean EKE; (e) zonally averaged EKE trend; (f) map of EKE trend (55.4\% of global area is significant above $95 \%$ confidence level). In panel (d), solid contours show positive EKE trends and dashed contours show negative EKE trends (contours of $\pm 5 \mathrm{~J} \mathrm{~m}^{-3}$ decade $^{-1}$ ). 


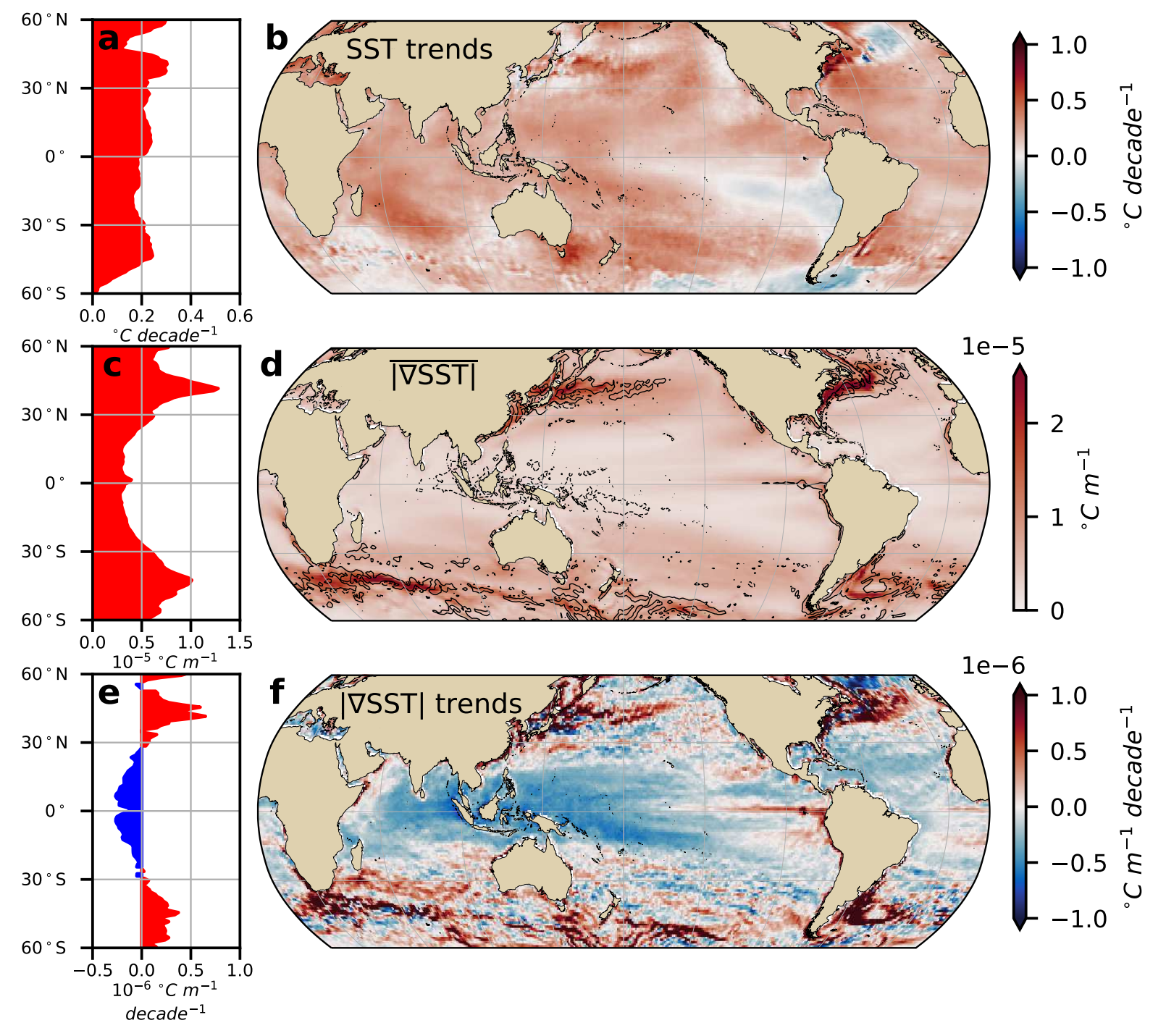

Figure 2 Sea Surface Temperature (SST) trends, mean SST gradient magnitude, and SST gradient magnitude trends between 1993-2019. (a) Zonally averaged SST trend; (b) map of SST trend (76.7\% of global area is significant above $95 \%$ confidence level; for the spatial distribution refer to Fig. S1); (c) zonally averaged time-mean of SST gradient magnitude; (d) map of time-mean of SST gradients magnitude; (e) zonally averaged SST gradient trend; (f) map of SST gradient trends $(81.6 \%$ of global area is significant above $95 \%$ confidence level). In panel (d), solid contours show positive SST gradient trends and dashed contours show negative SST gradient trends $( \pm 0.5 \times$ $10^{-6}{ }^{\circ} \mathrm{C} \mathrm{m}^{-1}$ decade ${ }^{-1}$ ). Note that the spatial pattern of SST gradient maps is independent of the temporal extent of the SST gradient record used to compute SST gradient trends (Fig. S2). 

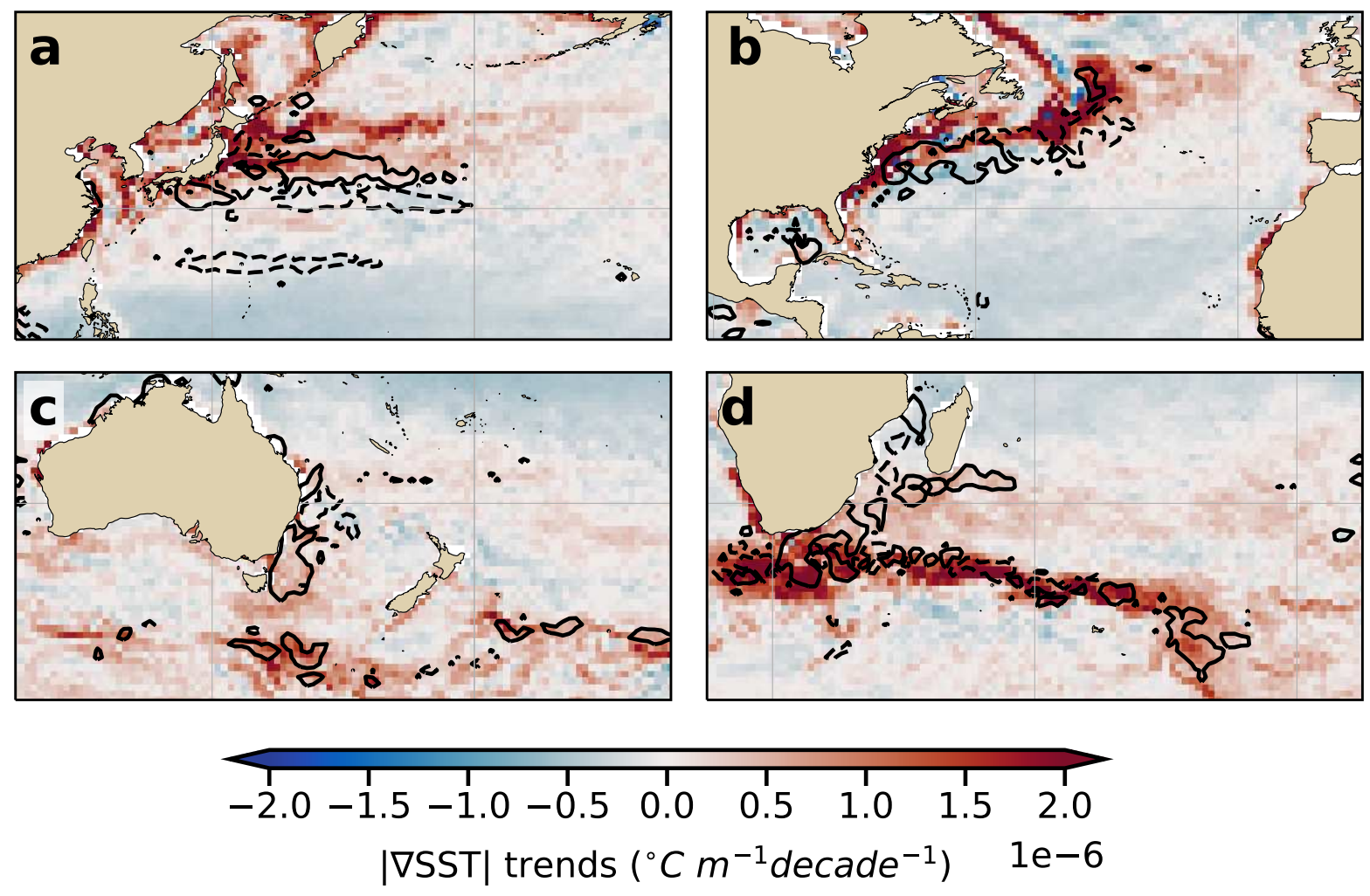

Figure 3 Regional maps of mesoscale SST gradient trends and EKE trends. (a) Kuroshio Current; (b) Gulf Stream; (c) East Australian Current; (d) Agulhas retroflection. In all panels, solid contours show positive EKE trends and dashed contours show negative EKE trends (contours of $\pm 5 \mathrm{~J} \mathrm{~m}^{-3}$ decade ${ }^{-1}$ ). 

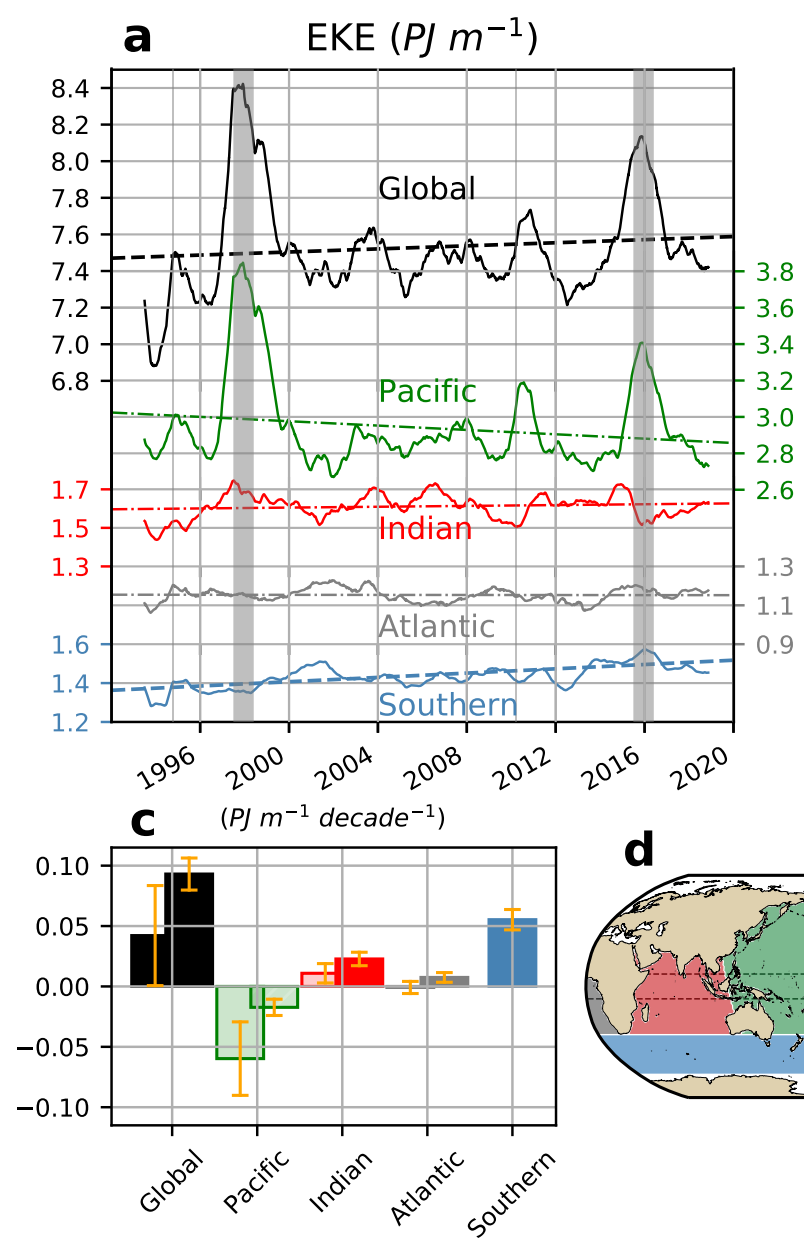

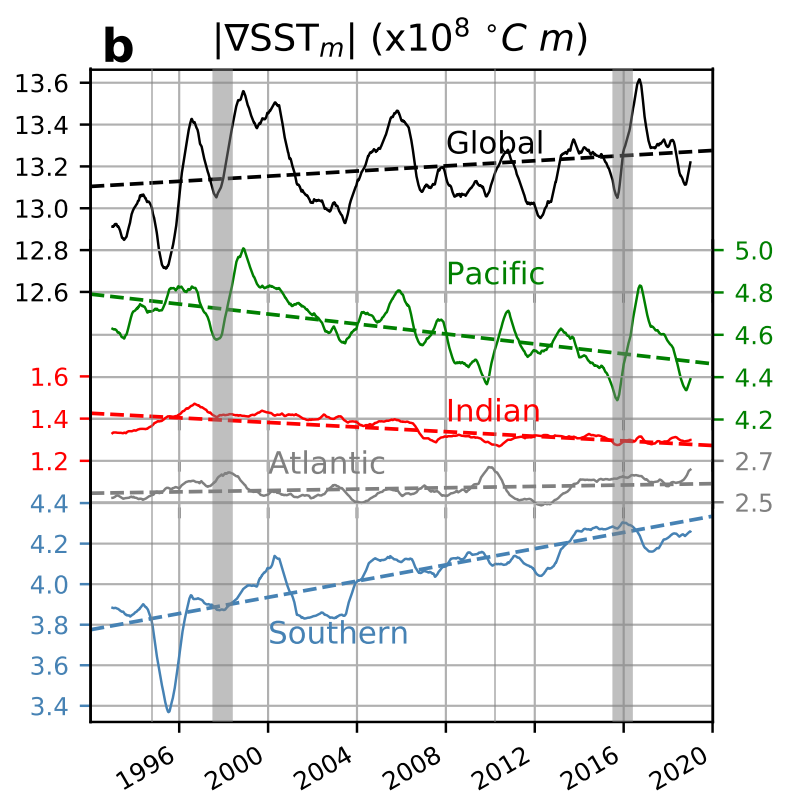

e $\left(\times 10^{8}{ }^{\circ} \mathrm{C} \mathrm{m}\right.$ decade $\left.{ }^{-1}\right)$
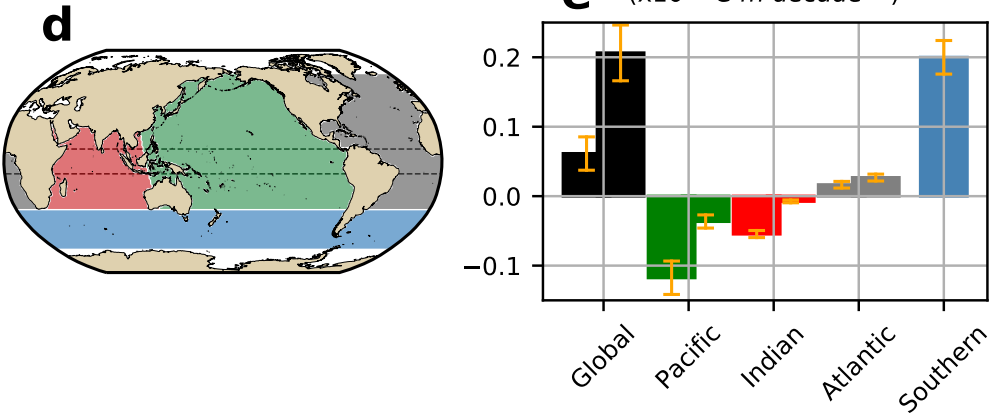

Figure 4 Time-series and linear trends of area integrated EKE and mesoscale SST gradients over various ocean basins. Global (solid black), Southern (blue), Indian (red), Pacific (green), and Atlantic Oceans (gray) and each region separately without the equatorial region (striped bars). (a) EKE time series. (b) mesoscale SST gradient time series. In panels (a) and (b), solid curves denote 12-month running averages for each basin, dashed lines correspond to significant time-series trend, dashed-dotted lines show insignificant time-series trend, and vertical gray bars indicate El Niño events (above the 90th percentile of MEl.v2 ${ }^{42}$ ). Note that the $y$ axis is discontinuous in panels (a) and (b). (c) Linear EKE trends for each basin. (d) Ocean basins; equatorial region $\left(9^{\circ} \mathrm{S}-9^{\circ} \mathrm{N}\right)$ is marked by the dashed lines. (e) Linear mesoscale SST gradient trends. In panels (c) and (e), standard errors are shown with orange bars and statistically significant trends (above $95 \%$ confidence level) denoted with solid bars while non-significant trends are translucent. 

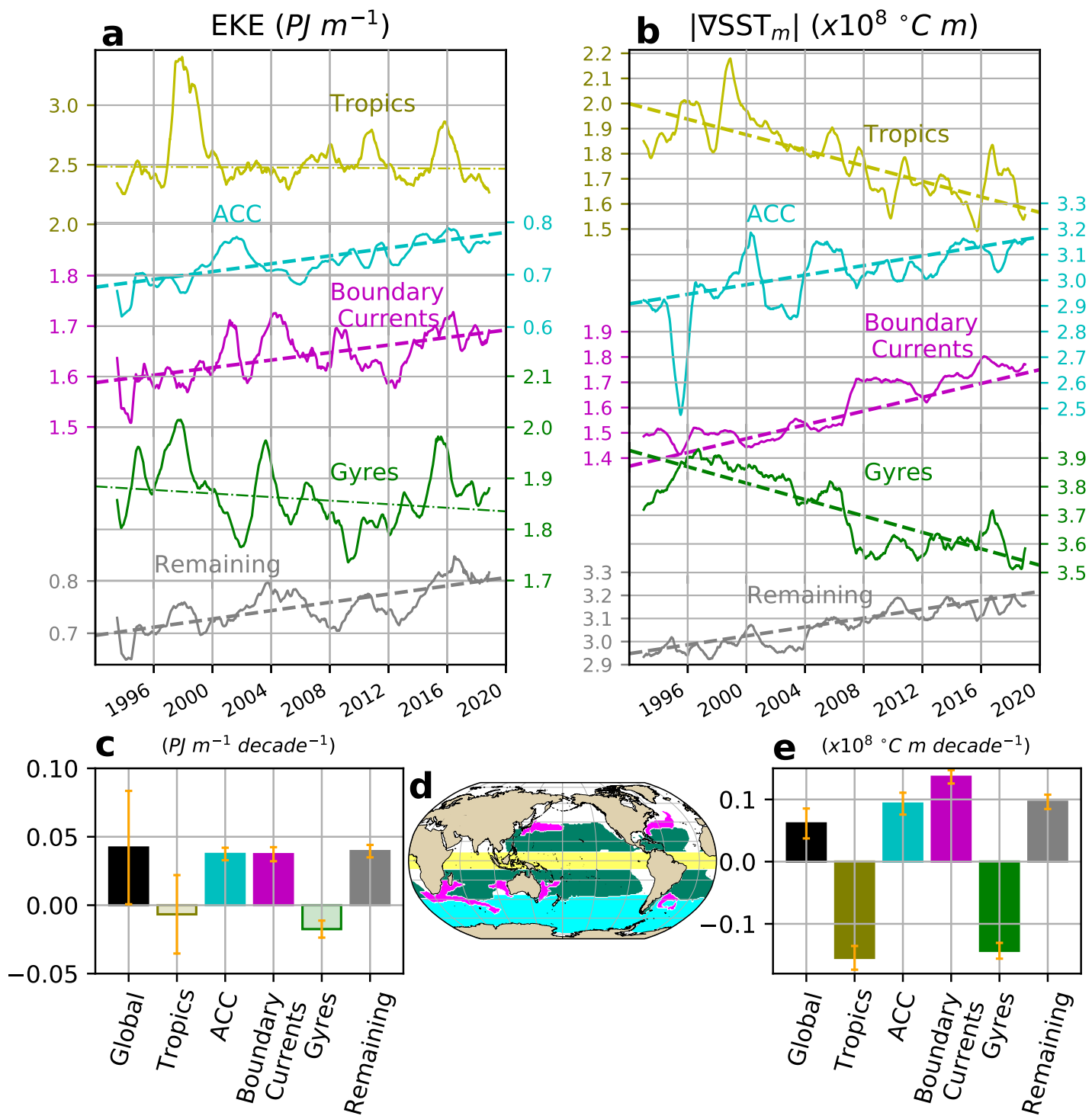

e $\left(x 10^{8}{ }^{\circ} \mathrm{C} \mathrm{m}\right.$ decade $\left.{ }^{-1}\right)$

Figure 5 Time-series and linear trends of integrated EKE and mesoscale SST gradients over dynamical regions. Global Ocean (black), Tropics (yellow), Antarctic Circumpolar Current (cyan), Boundary Currents and their extensions (magenta), Subtropical Ocean Gyres (green) and the rest (gray). (a) EKE time series. (b) mesoscale SST gradient time series. In panels (a) and (b), solid color curves are 12-month running averages of EKE and mesoscale SST gradients for each region, dashed lines correspond to significant time-series trend, and dashed-dotted lines show insignificant time-series trend. (c) Linear EKE trends for each dynamical region. (d) Definition of ocean regions. (e) Linear mesoscale SST gradient trends. Note that in panel (a) the top curve that corresponds to the Tropics has a different scale than the rest. In panels (c) and (e), standard errors are shown with orange bars and statistically significant trends (above $95 \%$ confidence level) are solid bars while non-significant trends are translucent. 


\section{Methods}

\section{Observational products}

The data used in this study includes Sea Surface Height, geostrophic velocities, and Sea Surface Temperature. The Archiving, Validation and Interpretation of Satellite Oceanographic data (AVISO+) gridded multimission sea surface height and geostrophic velocities have a horizontal resolution of $1 / 4^{\circ}$. Currents within the equatorial region $\left(5^{\circ} S-5^{\circ} N\right)$ are estimated using an equatorial $\beta$-plane approximation of the geostrophic equations ${ }^{43}$. National Oceanic and Atmospheric Administration - Optimum Interpolation Sea Surface Temperature (NOAA-OISST) has a horizontal resolution of $1 / 4^{\sqrt{23}}$. This dataset is constructed by combining observations from different products (e.g. satellites, ships, buoys, and ARGO floats).

These datasets have a quasi-global coverage $\left(65^{\circ} \mathrm{S}-65^{\circ} \mathrm{N}\right)$ and span 26 years, from January 1993 to December 2019. Anomalies were computed with respect to the record's climatology. We have verified that using a different period for defining the climatology does not change the observed trends in the anomaly fields. Moreover, through wavelet analysis (edge detection) of the time-series, we have verified that the observed trends are not a product of steps in the number of satellite missions and oceanographic observations.

\section{Kinetic Energy decomposition}

Kinetic energy density is decomposed into the energy density contained by the steady flow (time-mean) and that contained by the transient flow (time-varying). In other words, the surface geostrophic velocity components are split using a Reynolds decomposition into their time-mean 
$(\bar{u}, \bar{v})$ and time-varying components $\left(u^{\prime}=u-\bar{u}, v^{\prime}=v-\bar{v}\right)$, with bars denotating time-averages over the whole record. The KE is, therefore, decomposed as:

$$
\underbrace{\frac{1}{2} \rho_{0}\left(u^{2}+v^{2}\right)}_{\text {KE }}=\underbrace{\frac{1}{2} \rho_{0}\left(u^{\prime 2}+v^{\prime 2}\right)}_{\text {EKE }}+\underbrace{\frac{1}{2} \rho_{0}\left(\bar{u}^{2}+\bar{v}^{2}\right)}_{\text {MKE }}+\underbrace{\rho_{0}\left(\bar{u} u^{\prime}+\bar{v} v^{\prime}\right)}_{\text {Cross terms }},
$$

where we approximate the density of the seawater by the constant $\rho_{0}=1025 \mathrm{~kg} \mathrm{~m}^{-3}$. The energy contained in the time-varying component of the flow is known as the eddy kinetic energy (EKE), while the mean kinetic energy (MKE) is the energy of the time-mean flow.

Maps of EKE in this study correspond to the the time-mean EKE, defined as

$$
\overline{\operatorname{EKE}}(x, y)=\overline{\frac{1}{2} \rho_{0}\left(u^{\prime 2}+v^{\prime 2}\right)} .
$$

Time-series correspond to the surface integrated EKE (globally or over specific regions),

$$
\langle\operatorname{EKE}\rangle(t)=\iint_{A} \frac{1}{2} \rho_{0}\left(u^{\prime 2}+v^{\prime 2}\right) \mathrm{d} x \mathrm{~d} y
$$

where $A$ refers to the area of each geographical or dynamical region, $u^{\prime}$ and $v^{\prime}$ are anomalies of the surface geostrophic velocities provided by AVISO+, and angle brackets \langle\rangle denote the area integral.

\section{Sea surface temperature gradients}

Sea surface temperature (SST) gradients are decomposed into mesoscale (SST gradients with scales smaller than $3^{\circ}$ ) and large-scale (SST gradients with scales larger than $3^{\circ}$ ). To decompose the SST gradients, we first compute large-scale SST by using an average spatial convolution of 
$3^{\circ} \times 3^{\circ}$, and a 12 -months running average i.e.,

$$
\operatorname{SST}_{l s}(x, y, t)=\frac{\iint \widetilde{S S T}\left(x-x^{\prime}, y-y^{\prime}, t\right) K\left(x^{\prime}, y^{\prime}\right) \mathrm{d} x^{\prime} \mathrm{d} y^{\prime}}{\iint K\left(x^{\prime}, y^{\prime}\right) \mathrm{d} x^{\prime} \mathrm{d} y^{\prime}},
$$

where the SST field is convolved with a constant $3^{\circ} \times 3^{\circ}$ kernel $K$ and the tilde $\sim$ denotes a 12-month running average. The mesoscale SST is then defined as

$$
\mathrm{SST}_{m}=\mathrm{SST}-\mathrm{SST}_{l s}
$$

Small-scale EKE was computed analogously to the mesoscale SST but for the velocity components $\left(u_{m}=u-u_{l s}, v_{m}=v-v_{l s}\right)$.

The gradients of the large-scale and mesoscale SST are computed afterwards. The SST gradient magnitude is:

$$
|\nabla \mathrm{SST}|=\sqrt{\left(\frac{\partial \mathrm{SST}}{\partial x}\right)^{2}+\left(\frac{\partial \mathrm{SST}}{\partial y}\right)^{2}}
$$

with analogous expressions for $\mathrm{SST}_{m}$ and $\mathrm{SST}_{l s}$.

Computations of SST gradient time-series and time mean SST gradient trend maps are analogous to those of EKE, namely:

$$
\langle|\nabla \mathrm{SST}|\rangle(t)=\iint_{A}|\nabla \mathrm{SST}| \mathrm{d} x \mathrm{~d} y
$$

\section{Trends, significance \& uncertainties}

Linear trends are calculated using a linear least-squares regression model for spatial integrated time-series and geographic data. The fields are first coarsened to a $1^{\circ} \times 1^{\circ}$ grid, and then the linear trends are computed for each grid point. 
A modified Mann-Kendall test is used to assess statistical significance of trends, while prop-

erly taking into account the autocorrelation in the time-series ${ }^{24}$. The effective sample size for all the reported trends is always smaller than the actual sample size, due to autocorrelation of the time series. The significance of our observed trends for EKE and SST gradients is assessed via a t-student distribution test. If the probability of the trend is smaller than the confidence level ( $\alpha=0.05)$ then the null hypothesis is rejected and the estimated slope is considered significant at the $95 \%$ confidence level. The Pearson coefficient was also used to assess the significance of the trends. If the Pearson coefficient is smaller than 0.05 for a significance level of $95 \%$, then the existing trend is considered to be statistically significant. Finally, the reported uncertainties correspond to the standard error using the effective sample size from the Mann-Kendall test; that is, the standard deviation of the time-series divided by the square root of the effective sample size.

\section{Geographical and dynamical regions}

Geographical regions consist of the following ocean basins: the Southern Ocean, the Indian Ocean, the Pacific Ocean and the Atlantic Ocean. These ocean basins were defined to capture ocean processes at all scales. The ocean basin mask can be obtained from the repository https://github.com/josuemtzmo/EKE_SST_trends that contains all the data used for this study (refer to acknowledgments; filename ocean_basin_mask . nc).

Dynamical regions were defined from the climatological mean SSH and the mean KE. We define a mask for each dynamical region and overlay the masks on a global mask in the following order. First, the Antarctic Circumpolar Current (ACC) is defined as all regions south of $35^{\circ} \mathrm{S}$. 
Second, the subtropical ocean gyre definitions depend on the particular ocean basin they are located within: the Pacific Ocean gyres correspond to mean SSH above the $0.65 m$ contour; the Atlantic Ocean gyres correspond to mean SSH above the $0.36 \mathrm{~m}$ contour; and the Indian Ocean gyres correspond to mean SSH above the $0.60 m$ contour. All these values were tuned to capture approximately the same extension as the theoretical estimation of ocean gyres according to the Sverdrup balance. Third, the boundary currents and their extensions are defined as regions with mean KE above the $\sim 99$-th percentile $(2.8 \sigma)$. Lastly, the equatorial region is defined as the region between $9^{\circ} \mathrm{S}$ and $9^{\circ} \mathrm{N}$. The dynamical regional mask can be obtained from the repository containing all the data used for this study (refer to acknowledgments; filename ocean_processes_mask.nc). 
Figures

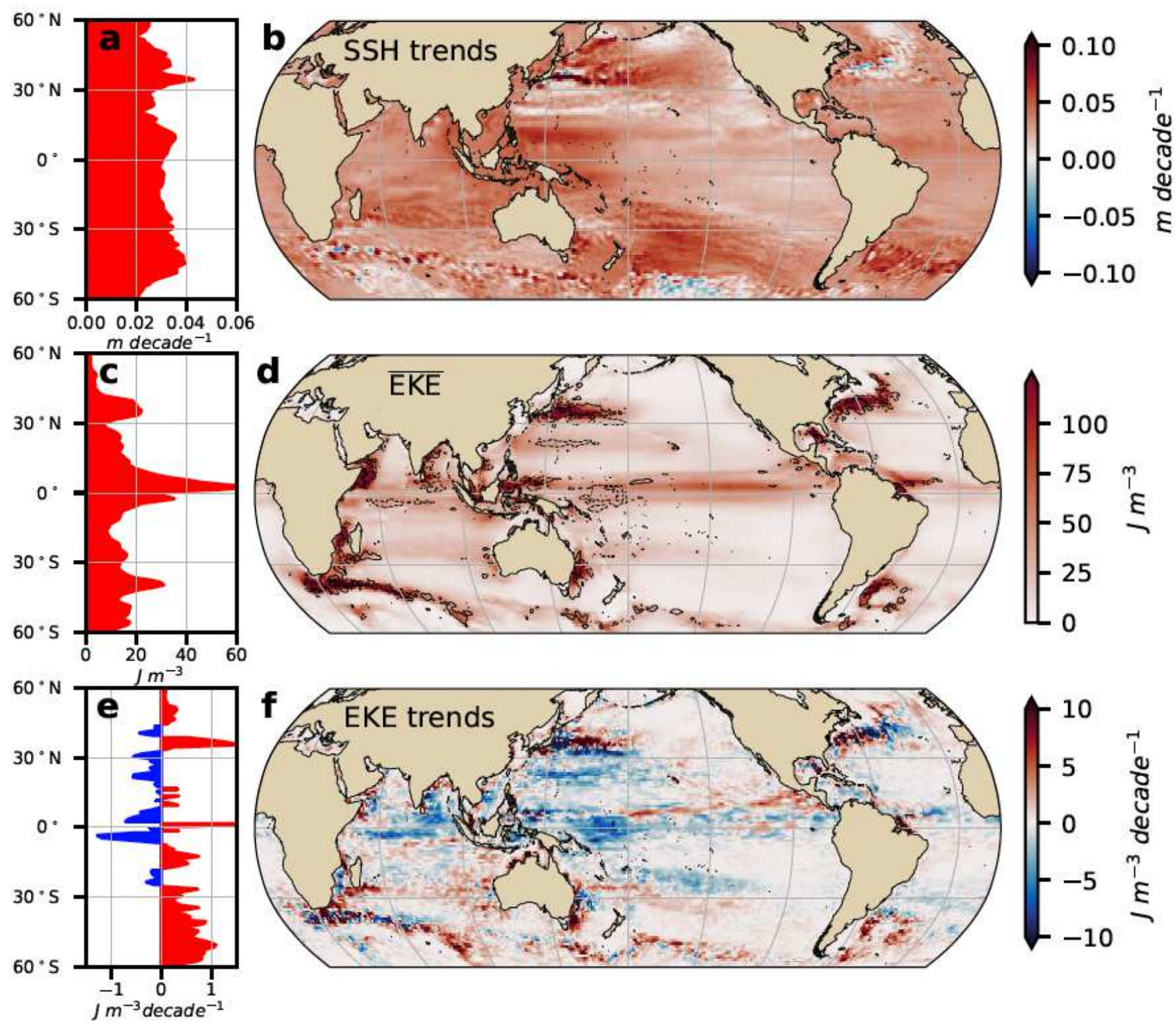

Figure 1

Sea Surface Height trend, mean surface Eddy Kinetic Energy and surface Eddy Kinetic Energy trend between 1993-2019 (a) Zonally averaged SSH trend; (b) map of SSH trend (92.1\% of global area is significant above 95\% confidence level; for spatial distribution refer to Fig. S1); (c) zonally averaged mean EKE; (d) map of mean EKE; (e) zonally averaged EKE trend; (f) map of EKE trend (55.4\% of global area is significant above $95 \%$ confidence level). In panel (d), solid contours show positive EKE trends and dashed contours show negative EKE trends (contours of $\pm 5 \mathrm{~J} \mathrm{~m}-3$ decade- 1 ). Note: The designations employed and the presentation of the material on this map do not imply the expression of any opinion whatsoever on the part of Research Square concerning the legal status of any country, territory, city or area or of its 
authorities, or concerning the delimitation of its frontiers or boundaries. This map has been provided by the authors.

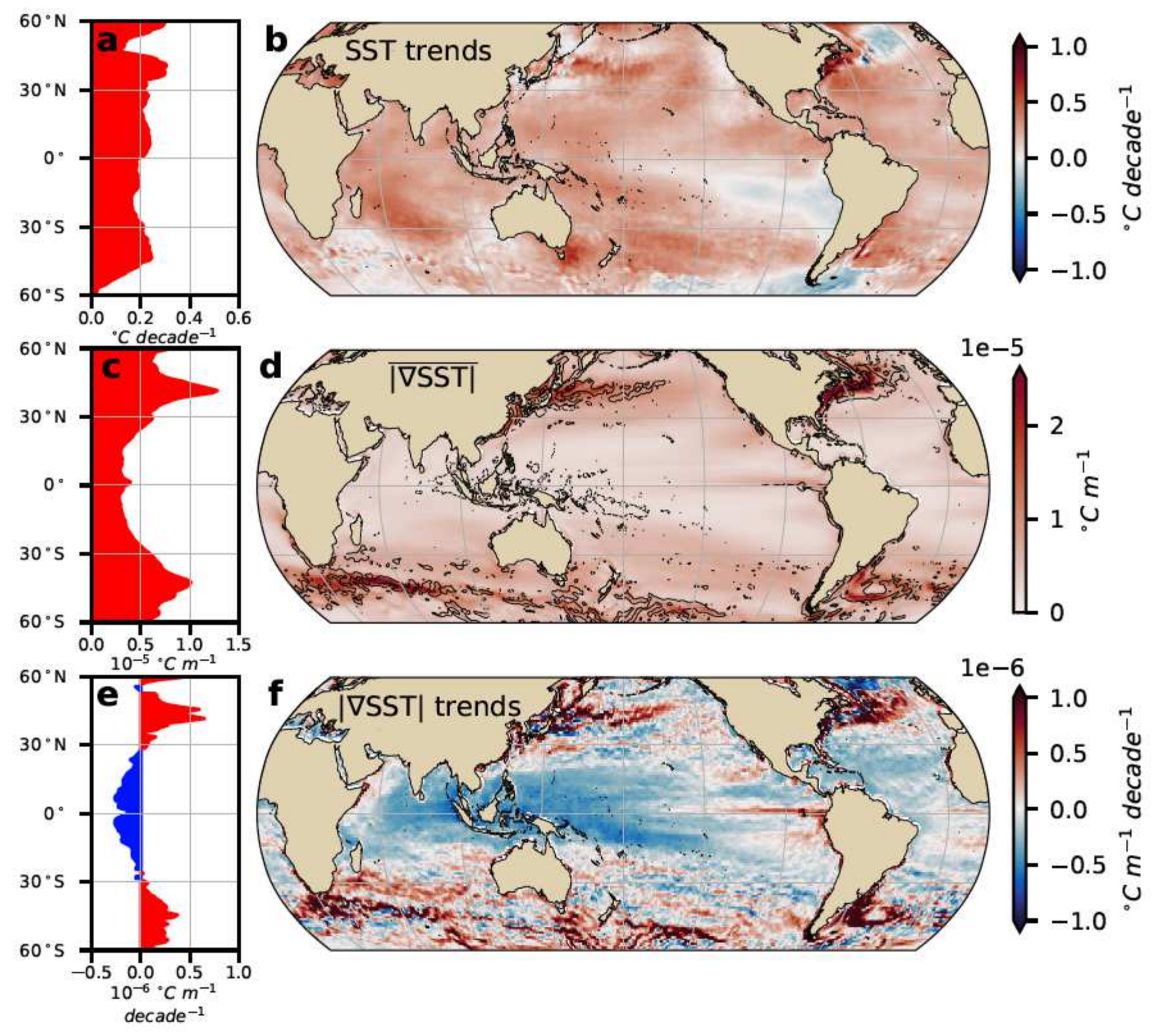

Figure 2

Sea Surface Temperature (SST) trends, mean SST gradient magnitude, and SST gradient magnitude trends between 1993-2019. (a) Zonally averaged SST trend; (b) map of SST trend (76.7\% of global area is significant above 95\% confidence level; for the spatial distribution refer to Fig. S1); (c) zonally averaged time-mean of SST gradient magnitude; (d) map of time-mean of SST gradients magnitude; (e) zonally averaged SST gradient trend; (f) map of SST gradient trends ( $81.6 \%$ of global area is significant above $95 \%$ confidence level). In panel (d), solid contours show positive SST gradient trends and dashed

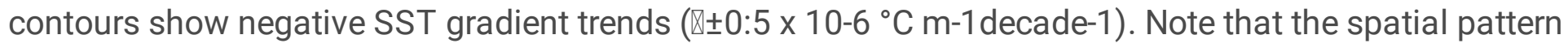
of SST gradient maps is independent of the temporal extent of the SST gradient record used to compute 
SST gradient trends (Fig. S2).Note: The designations employed and the presentation of the material on this map do not imply the expression of any opinion whatsoever on the part of Research Square concerning the legal status of any country, territory, city or area or of its authorities, or concerning the delimitation of its frontiers or boundaries. This map has been provided by the authors.
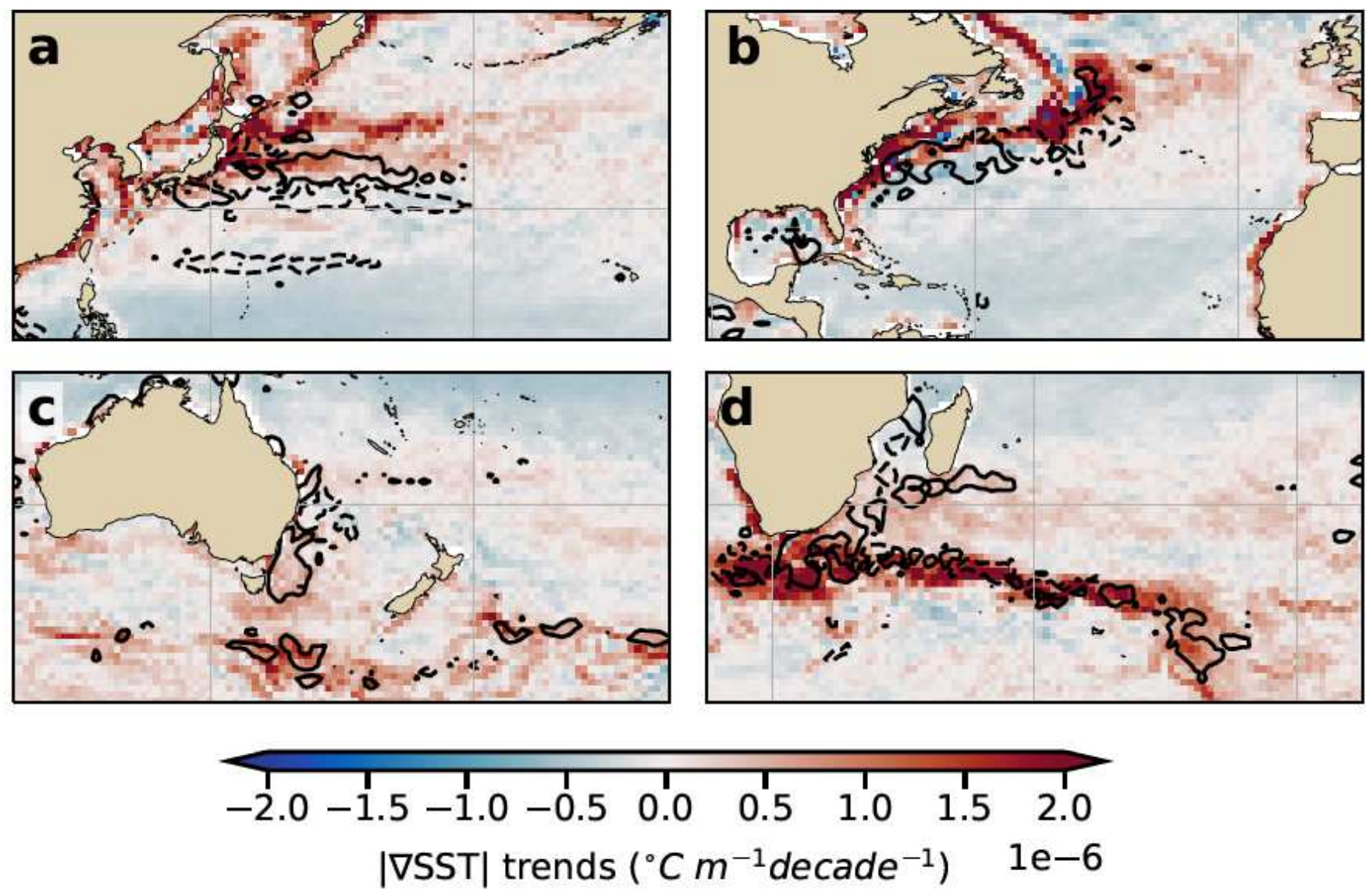

\section{Figure 3}

Regional maps of mesoscale SST gradient trends and EKE trends. (a) Kuroshio Current; (b) Gulf Stream; (c) East Australian Current; (d) Agulhas retroflection. In all panels, solid contours show positive EKE trends and dashed contours show negative EKE trends (contours of $\pm 5 \mathrm{~J} \mathrm{~m}-3$ decade- 1 ). Note: The designations employed and the presentation of the material on this map do not imply the expression of any opinion whatsoever on the part of Research Square concerning the legal status of any country, territory, city or area or of its authorities, or concerning the delimitation of its frontiers or boundaries. This map has been provided by the authors. 


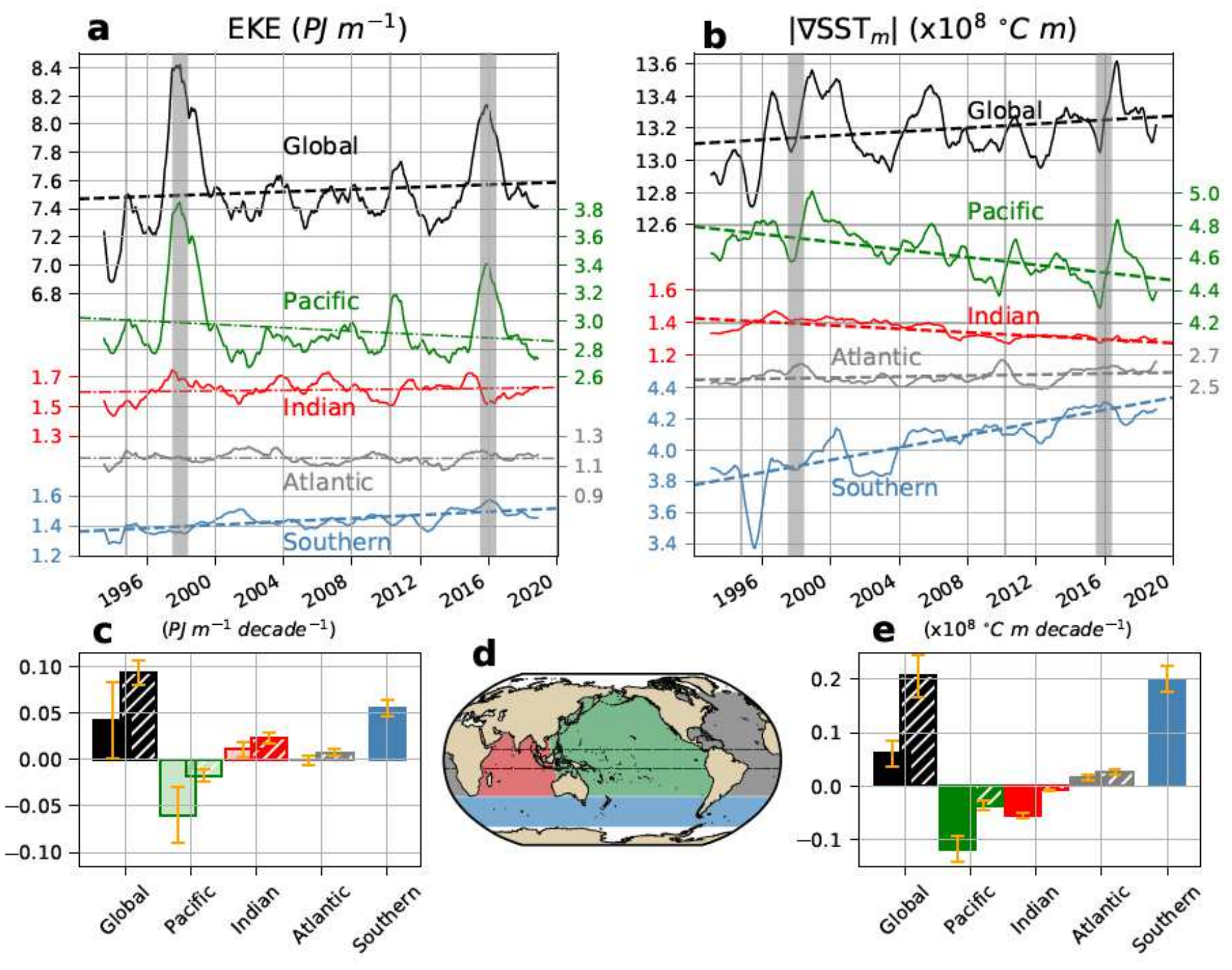

Figure 4

Time-series and linear trends of area integrated EKE and mesoscale SST gradients over various ocean basins. Global (solid black), Southern (blue), Indian (red), Pacific (green), and Atlantic Oceans (gray) and each region separately without the equatorial region (striped bars). (a) EKE time series. (b) mesoscale SST gradient time series. In panels (a) and (b), solid curves denote 12-month running averages for each basin, dashed lines correspond to significant time-series trend, dashed-dotted lines show insignificant time-series trend, and vertical gray bars indicate El Niño events (above the 90th percentile of MEl.v242). Note that the $y$ axis is discontinuous in panels (a) and (b). (c) Linear EKE trends for each basin. (d) Ocean

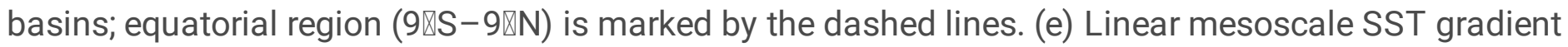
trends. In panels (c) and (e), standard errors are shown with orange bars and statistically significant trends (above 95\% confidence level) denoted with solid bars while non-significant trends are translucent. Note: The designations employed and the presentation of the material on this map do not imply the expression of any opinion whatsoever on the part of Research Square concerning the legal status of any 
country, territory, city or area or of its authorities, or concerning the delimitation of its frontiers or boundaries. This map has been provided by the authors.
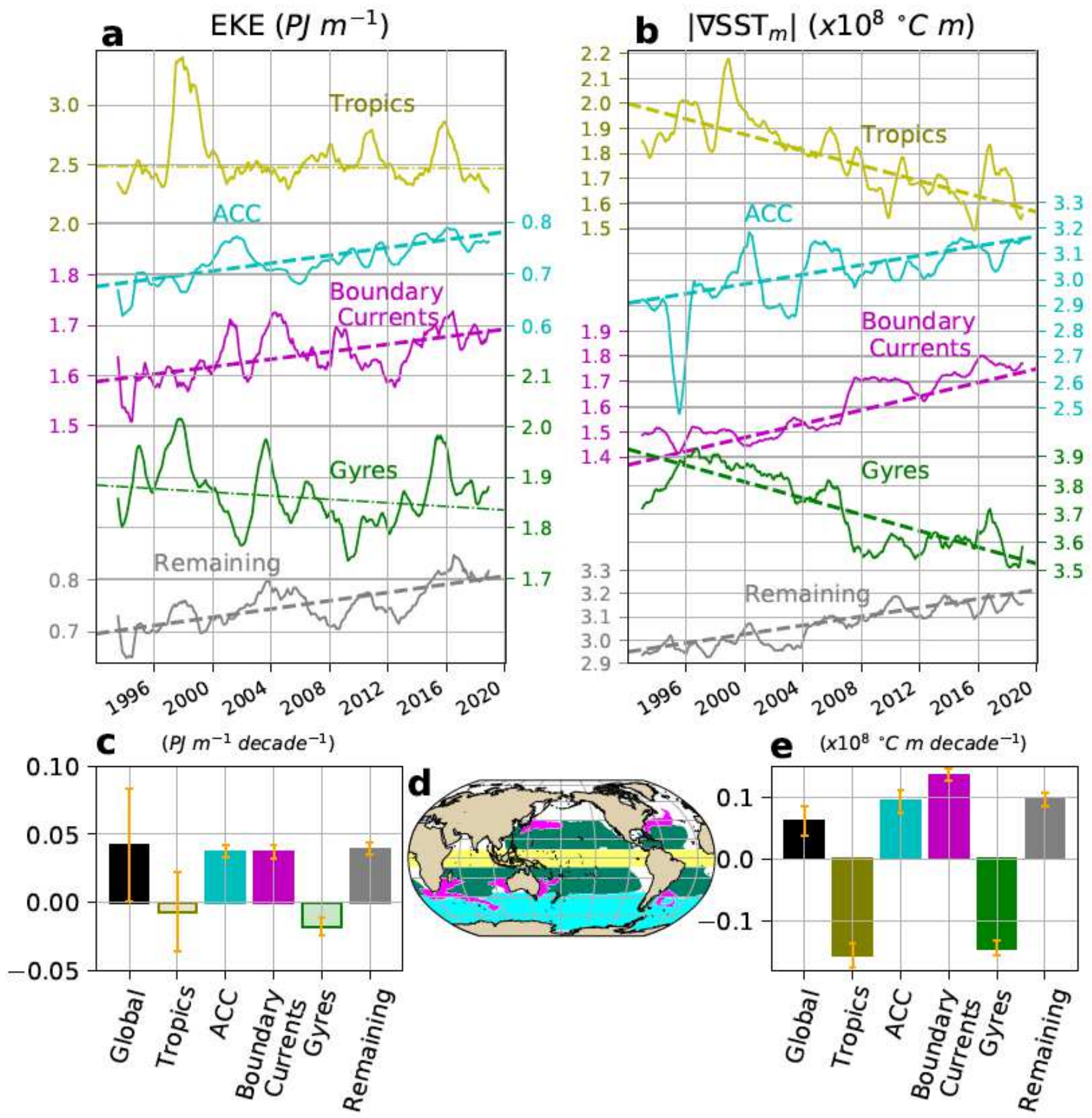

\section{e $\left(x 10^{8}{ }^{\circ} \mathrm{C} \mathrm{m}\right.$ decade $\left.{ }^{-1}\right)$}

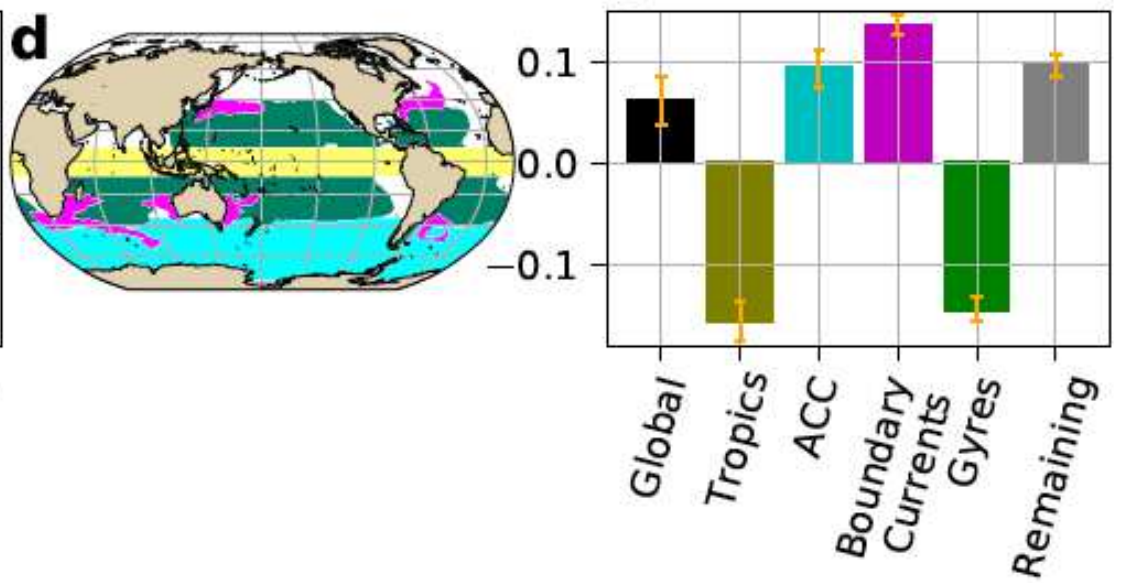

Figure 5

Time-series and linear trends of integrated EKE and mesoscale SST gradients over dynamical regions. Global Ocean (black), Tropics (yellow), Antarctic Circumpolar Current (cyan), Boundary Currents and their extensions (magenta), Subtropical Ocean Gyres (green) and the rest (gray). (a) EKE time series. (b) mesoscale SST gradient time series. In panels (a) and (b), solid color curves are 12-month running averages of EKE and mesoscale SST gradients for each region, dashed lines correspond to significant 
time-series trend, and dashed-dotted lines show insignificant time-series trend. (c) Linear EKE trends for each dynamical region. (d) Definition of ocean regions. (e) Linear mesoscale SST gradient trends. Note that in panel (a) the top curve that corresponds to the Tropics has a different scale than the rest. In panels (c) and (e), standard errors are shown with orange bars and statistically significant trends (above $95 \%$ confidence level) are solid bars while non-significant trends are translucent. Note: The designations employed and the presentation of the material on this map do not imply the expression of any opinion whatsoever on the part of Research Square concerning the legal status of any country, territory, city or area or of its authorities, or concerning the delimitation of its frontiers or boundaries. This map has been provided by the authors.

\section{Supplementary Files}

This is a list of supplementary files associated with this preprint. Click to download.

- OceancurrentchangesJMMsupplementary.pdf 